\title{
OS CPPD Nursing Science \\ EFFECTIVENESS OF NURSE LED INTERVENTION ON KNOWLEDGE REGARDING PATIENT SAFETY GOALS IN HOSPITAL
}

\section{Mr. Praveen Sharma*}

Mrs. Anisha Naire
M.Sc. Nursing final year, medical surgical nursing, SAIMS College of Nursing Indore, (M.P.). ${ }^{*}$ Corresponding Author
Associate professor, medical surgical nursing, SAIMS College of Nursing Indore, (M.P.).

ABSTRACT Patient safety is another healthcare issue in the medical care organization that incorporates the reducing and preventing Medical fault that regularly prompts destructive patient safety out comes, so that why it is conduct a pre experimental study to assess the effectiveness of nurse led intervention on knowledge regarding patient safety goals in hospital among staff nurse at selected hospital, Indore. The aim of study to assess the effectiveness of nurse led intervention. In this study 80 staff nurse was selected by using Non probability convenient sampling techniques. Pre- interventional knowledge level was assessed by self structured knowledge questionnaire. The data collect was analyzed by using descriptive and inferential statistics. The average (Mean $=$ standard deviation) knowledge scoring in pre-test to measure the pre-existed knowledge about patient safety goal in hospital to be $14.09 \pm 4.45$ points and knowledge score at post test found to be 27.74 \pm 3.16 points. The mean difference of 13.65 points in knowledge scoring between pre - interventional and post - interventional. The $t$ value is 22.37 at df 79 (6.1) at 0.05 level of significance. Which clearly showed the effectiveness of nurse led intervention on knowledge of staff nurse regarding patient safety goal in hospital. The positive mean difference of knowledge score shows that information booklet was effective.

KEYWORDS : Patient safety, nurse led intervention, information booklet, effectiveness, assess, staff nurse

\section{INTRODUCTION:}

Patient safety is another healthcare issue in the medical care organization that incorporates the reducing and preventing medical fault that regularly prompts destructive patient safety out comes. Health care has gotten more proficient use of new technology and treatments, which needs embracing With the global patient safety goals to improve the patient safety climate to recreate worldwide rivalry and to expand the upper hands of health care organization at the public and global evaluations. Patient Safety Goals set by Joint Commission International is a basic component in the Accreditation cycle. Meeting the Patient Safety Goals will assist with seeing how the organization can meet the necessities of the six goals, which include the accompanying vital patient safety subjects: improving the accuracy of patient identification; making communication more effective; improving the safety of utilizing high-alert medication; ensuring right site, right procedure, right person surgery; reducing the riskof health care associated Infection; and reducing the risk of patient harm resulting from Joint Commission National Patient Safety Goals On four out of seven study things estimating fulfillment and selfrevealed certainty, the extent of SE assistants reacting decidedly was significantly higher $(\mathrm{p}<0.05)$ than the part of SQ understudies. SE assistants showed a mean 4.79 (36.6\%) NPSG-agreeable practices (out of 13 aggregate), while SQ understudies finished a mean $4.17(32.0 \%)$ $(\mathrm{p}=0.09)$. Among those in careful fields, SE assistants demonstrated a mean 5.67 (43.6\%) NPSG-agreeable practices, while SQ understudies completed a mean $2.33(17.9 \%)(\mathrm{p}=0.015)$. Centre gathering information demonstrates that SE was more logically applicable than SQ, and essentially additionally captivating.

\section{OBJECTIVES OFTHE/STUDY}

1. To assess the pre-interventional knowledge of staff nurse regarding patient safety goal in hospital at selected hospital, Indore.

2. To assess the post-interventional knowledge of staff nurse regarding patient safety goals in hospital at selected hospital, Indore.

3. To Find out the significant difference between pre-interventional and post interventional knowledge of staff nurse regarding patient safety goals in hospital at selected hospital, Indore.

4. To determine the association between pre-interventional knowledge of staff nurse regarding patient safety goals in hospital with their selected demographic variables at selected hospital, Indore

\section{HYPOTHESIS}

1. $\mathbf{H}_{01}$ :- There is no significance difference between the mean preinterventional and the mean post-interventional knowledge score regarding patient safety goals in hospital among staff nurse at

\section{selected hospital, Indore.}

2. $\mathbf{H}_{\mathrm{A} 1}$ :- There will be significant difference between the mean preinterventional and the post-interventional knowledge score regarding patient safety goals in hospital among staff nurse at selected hospital, Indore.

3. $\mathbf{H}_{\mathbf{A} 2}$ :- There will be significant association between preinterventional knowledge of staff nurse regarding patient safety goals in hospital with their selected demographic variables at selected hospital, Indore.

\section{METHODOLOGY}

A quantitative evaluative research approach with pre-experimental one group pre-test post-test research design was used in study, 80 staff nurse working in SAIMS hospital Indore (M.P.), were selected by using non- probability convenient sampling techniques. Who were 22 year of age and above, and able to read and write Hindi and English language.

\section{RESULT}

The average $($ Mean = standard deviation) knowledge scoring in pretest to measure the pre-existed knowledge about patient safety goal in hospital to be $14.09 \pm 4.45$ points and knowledge score at post test found to be $27.74 \pm 3.16$ points. The mean difference of 13.65 points in knowledge scoring of pre-interventional and post-interventional. The $t$ value is 22.37 at $\mathrm{df} 79(6.1)$ at 0.05 level of significance. Which clearly showed the effectiveness of nurse led intervention on knowledge of staff nurse regarding patient safety goal in hospital. The positive mean difference of knowledge score shows that information booklet was effective

Table No 4.1: Frequency And Percentage Distribution Of Selected Demographic Variables Of Staff Nurse. $(n=80)$

\begin{tabular}{|l|l|l|l|l|}
\hline $\begin{array}{l}\text { S. } \\
\text { No. }\end{array}$ & $\begin{array}{l}\text { Demographic } \\
\text { Variables }\end{array}$ & Particular & $\begin{array}{l}\text { Frequency } \\
\text { (f) }\end{array}$ & $\begin{array}{l}\text { Percentage } \\
\text { (\%) }\end{array}$ \\
\hline 1. & Age in year & A. 22-25 & 26 & 32.5 \\
& & B. 26-29 & 42 & 52.5 \\
& & C. 30-33 & 08 & 10 \\
D. 34 and above & 04 & 05 \\
\hline 2. & Gender & A. Male & 32 & 40 \\
& & B. Female & 48 & 60 \\
\hline 3. & Marital Status & A. Married & 56 & 70 \\
& & B. Unmarried & 24 & 30 \\
\hline 4. & Professional & A. GNM & 26 & 32.5 \\
& qualification & B .Post B.sc. & 14 & 17.5 \\
& nursing & C. B.Sc. nursing & 36 & 45 \\
& & D. M.Sc. nursing & 04 & 5 \\
\hline
\end{tabular}


Volume - 11 | Issue - 01 | January - 2021 | PRINT ISSN No. 2249 - 555X | DOI : 10.36106/ijar

\begin{tabular}{|c|c|c|c|c|}
\hline 5. & $\begin{array}{l}\text { Clinical } \\
\text { working area }\end{array}$ & $\begin{array}{l}\text { A. General ward } \\
\text { B. Specialized } \\
\text { unit } \\
\text { C. Intensive care } \\
\text { unit } \\
\text { D. Operation } \\
\text { theatre }\end{array}$ & 21 & $\begin{array}{l}58.75 \\
10 \\
26.25 \\
5\end{array}$ \\
\hline 6 & $\begin{array}{l}\text { Total year of } \\
\text { working } \\
\text { experience }\end{array}$ & $\begin{array}{l}\text { A. Less than } 1 \\
\text { year } \\
\text { B. } 1 \text {-3 year } \\
\text { C. } 4 \text {-6 year } \\
\text { D. More than } 6 \\
\text { year }\end{array}$ & $\begin{array}{l}22 \\
33 \\
18\end{array}$ & $\begin{array}{l}27.5 \\
41.25 \\
22.5 \\
\\
8.75\end{array}$ \\
\hline 7. & \begin{tabular}{|l|} 
Previous \\
knowledge \\
about Patient \\
safety goal?
\end{tabular} & $\begin{array}{l}\text { A. Yes } \\
\text { B. No }\end{array}$ & $\begin{array}{l}22 \\
58\end{array}$ & $\begin{array}{l}27.5 \\
72.5\end{array}$ \\
\hline
\end{tabular}

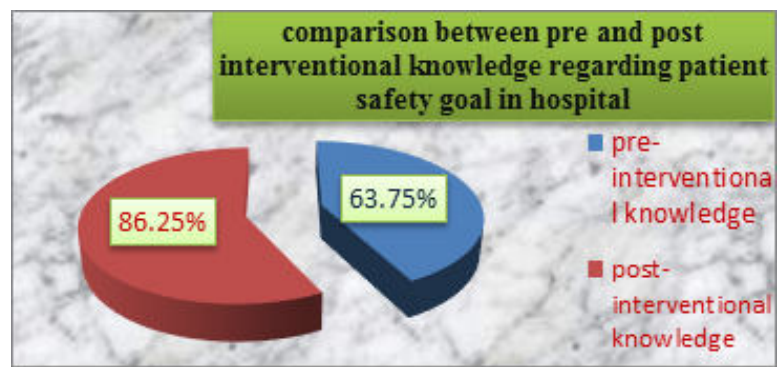

Figure- 4.4.3: 3d Pie Diagram Shows Categorical Comparison Between Pre And Post- Intervention Knowledge Regarding Patient Safety Goal In Hospital

\section{LIMITATIONS}

1. The study is limited to knowledge of the staff nurse regarding patient safety goal at selected hospital Indore.

2. The sample size was small to generalized the finding of the study

\section{REFERENCES}

1. Brunner \& Siddhartha. (2003). Text book of medical surgical nursing $10^{\text {th }}$ edition Philadelphia: JB Lippincott publication

2. Lewis Dirksen heitkemper bucher (2012). Medical surgical nursing $6^{\text {th }}$ edition newyork Lewis Dirksen heitkemper bucher (2012). Medical surgical nursing 6 edition newyork mobsipublication

3. Burke, L; Kaur S; and Kumar A.K. (2013). Text book of medical surgical nursing second edition Lanadari : Lotus publisher.

4. Black J.M. \& J.H. (2005). Medical surgical nursing $10^{\text {th }}$ edition Philadelphia: WB Saunders publication

5. T.N.A.I (2015). Text book of fundamental nursing $10^{\text {th }}$ edition. 